\title{
UM CURRÍCULO INCLUSIVO É POSSIVEL?
}

IS AN INCLUSIVE

CURRICULUM A REAL

POSSIBILITY?

\section{¿ES POSIBLE UN \\ CURRÍCULUM INCLUSIVO?}

Resumo: Atualmente, o vocabulário da inclusão se aplica espontaneamente, com maior frequência, às pessoas e aos grupos humanos bem mais do que entre as coisas a incluir. No contexto internacional, a declaração de Salamanca, de 1994, abriu o caminho para a evolução dessas concepções educativas inclusivas para as crianças com necessidades particulares, em oposição à educação especial. Já em 2020, os relatórios da UNESCO inauguram uma outra etapa, que passa a valorizar o conjunto dos aprendizes em sua diversidade. A sociologia britânica do curriculum distingue tipos diferentes de curriculum: formal, real, oculto. Nesse artigo, utilizamos essas categorias para analisar os resultados de uma pesquisa europeia sobre a educação inclusiva desde a primeira infância. A observação detalhada da situação educativa num jardim de infância de Paris mostra a existência de um currículo real flexível, que permite uma improvisação educativa aberta à diversidade das crianças. Tais orientações curriculares inclusivas acarretam o desenvolvimento de um novo perfil de professor inclusivo.

Palavras-chave: Inclusão. Sociologia do currículo. Educação da primeira infância. Currículo inclusivo. Professor inclusivo.

Recebido em: 11/03/2021

Aceito em: 24/03/2021

Publicação em: 23/03/2021
Eric Plaisance

Doctorat d'Etat ès Lettres et Sciences

Humaines

Professeur émérite à l'Université Paris Descartes, France.

E-mail: erplaisance@gmail.com

Orcid: http://orcid.org/0000-0002-7047-

4194

Como citar este artigo:

PLAISANCE, E. UM CURRICULO INCLUSIVO É POSSIVEL?. Revista Espaço do Currículo, v. 14, n. 1, 2021. p. 1-16. ISSN2177-2886. DOI: 10.22478/ufpb.1983-1579.2021v14n1.58096. 
Summary: Today, the vocabulary of inclusion applies spontaneously to people and human groups more than to the things to be included among them. In the international context, the Salamanca Declaration of 1994 marks a starting point for the evolution of inclusive educational designs for children with special needs, as opposed to special education. The Unesco reports in 2020 dedicate another stage that values all learners in their diversity. British curriculum sociology discerns different types of curriculum: formal, real, hidden; which allows the analysis of the results of a European survey on inclusive early childhood education. A detailed observation of an educational situation in a kindergarten in Paris shows a real flexible curriculum, involving educational improvisation open to the diversity of children. These inclusive curricular orientations require a new profile of inclusive teacher.

Key Words: Inclusion. Curriculum Sociology. Early Chidhood Education. Inclusive Curriculum. Inclusive Teacher.

Resumen: Actualmente, el vocabulario de inclusión se aplica de manera espontánea, con mayor frecuencia, a personas y grupos humanos mucho más que entre las cosas a incluir. En el contexto internacional, la Declaración de Salamanca de 1994 allanó el camino para la evolución de estos conceptos educativos inclusivos para niños con necesidades particulares, frente a la educación especial. En 2020, los informes de la UNESCO inauguran otra etapa, que comienza a valorar el conjunto de aprendices en su diversidad. La sociología curricular británica distingue diferentes tipos de currículum: formal, real, oculto. En este artículo, utilizamos estas categorías para analizar los resultados de una encuesta europea sobre educación inclusiva desde la primera infancia. La observación detallada de la situación educativa en un jardín de infancia en París muestra la existencia de un currículo realmente flexible, que permite una improvisación educativa abierta a la diversidad de los niños. Estas pautas curriculares inclusivas conducen al desarrollo de un nuevo perfil docente inclusivo.

Palabras clave: inclusión. Sociología del currículum. Educación de la primera infancia. Currículo inclusivo. Docente inclusivo.

noção de inclusão se banalizou de tal modo já há vários anos, que seu uso sofreu
importantes modificações. Nos mais variados campos, ela passou a se aplicar mais às
pessoas ou aos grupos humanos do que às coisas, como requer seu uso tradicional [inclusão de uma coisa na outra]. Mais do que outros países, desde os anos 2000, o Brasil apresentou uma grande originalidade, ao generalizar esse vocabulário da inclusão às políticas governamentais e locais em favor de diferentes minorias, tanto nas questões de trabalho e de transporte, como no acesso a diferentes serviços, e ainda, sem dúvida, na educação para todos, sobretudo para aqueles que pertencem aos grupos marginalizados. A pandemia de 2020 veio, no entanto, enfatizar essas interrogações sobre a inclusão. Devido à sua atualidade, sentimos hoje em dia necessidade de dar prosseguimento à reflexão sobre como ela se opera na área da educação. A pandemia não somente desestabilizou a sociedade, acentuando suas desigualdades sociais e suas exclusões, mas ampliou as dificuldades das crianças dos grupos mais pobres, colocando um novo desafio no que se refere ao laço social e à educação. Assim, as atividades educacionais passaram a representar uma aposta essencial nas chamadas políticas inclusivas e na redefinição das orientações curriculares. A questão que se coloca é então a seguinte: Como abordar essa questão do currículo, tão premente para os professores e os gestores? Um "currículo inclusivo" teria sentido nesse contexto?

\section{VOCABULÁRIO DA INCLUSÃO}

O uso atual do vocabulário da inclusão apresenta muitas ambiguidades, especialmente no Brasil. Podemos perguntar: seria ele um vocabulário formal, sem sentido, composto de palavras vazias, ou pior, uma máscara de retrocesso? O novo decreto da Presidência da República sobre a educação especial, publicado no dia 30 de setembro de 2020, se intitula: "Política nacional de educação especial: equitativa, inclusiva e com aprendizado ao longo da vida" (Decreto n¹0.502). Essa formulação nos parece operar uma estranha mistura entre as orientações tradicionais ligadas à educação especial e as orientações mais modernas em direção à educação inclusiva, alinhada às tendências internacionais. Muitos especialistas, aliados a alguns grupos de defesa das pessoas com deficiência (como as pessoas com síndrome de Down) denunciam, neste texto, um grande retrocesso no sentido de medidas segregativas, na medida em que 
preconizam escolas e classes especiais, separadas do quadro normal. A argumentação do decreto é a seguinte: a educação especial se destina "aos educandos cujo desenvolvimento, quando incluídos em escolas regulares inclusivas, não apresenta benefícios, e que têm uma demanda por apoios múltiplos e contínuos". E o antigo argumento em favor da segregação, da separação das crianças que tem mais dificuldades, sem colocar a questão fundamental das transformações das escolas comuns, das modalidades de apoio nas escolas, e da formação dos professores. Para esse documento oficial, é bem mais fácil voltar à segregação, em vez de propor a definição de uma política publica ambiciosa da educação, na qual algumas crianças possam inclusive beneficiar-se de certas medidas precisas².

Por enquanto, além da situação brasileira, de um modo geral, a palavra inclusão apresenta certas ambiguidades. A origem latina da palavra ("in-cludere" significa "in-cluir", no sentido de en-cerrar) nos confronta à noção de fechamento, de clausura. O termo "claustro" indica um espaço delimitado, do qual apenas alguns fazem parte, mas que é fechado aos outros. Essa formulação nos parece um paradoxo, na medida em que a ideologia atual da inclusão pressupõe, ao contrário, a abertura à diversidade, a possibilidade de que cada um venha a pertencer às instituições comuns (CURY, 2002, 2009). Por essa e outras razões, alguns autores preferem abster-se de usar o substantivo inclusão, em prol do adjetivo inclusivo ou inclusiva. Charles Gardou, professor da Universidade de Lyon na França, pensa igualmente que a inclusão implica uma ideia de fechamento, de reclusão. Ele fornece inúmeros exemplos nesse sentido: em biologia (inclusão fetal), em citologia (inclusão celular), em odontologia (um dente incluso), em mineralogia ou em metalurgia (um corpo estranho indesejável). Ele considera o adjetivo inclusivo mais adequado e pertinente, na medida em que ele traduz uma dupla recusa: por um lado, a de uma sociedade excludente, da qual somente as pessoas "não deficientes" reivindicariam a propriedade; e por outro, a do afastamento daqueles que são considerados "incômodos, estranhos, inadequados". Gardou define uma organização inclusiva "quando modula esse funcionamento social, que se flexibiliza para oferecer, no seio do conjunto comum, uma casa para todos" (GARDOU, 2018, p. 26). Sua ambição se alarga quando ele defende a visão de uma sociedade inclusiva, que se constrói "sem privilégios, sem exclusividades ou exclusões" (ibid., p.86).

A oposição entre integração e inclusão é um outro ponto essencial para a clarificação dessa ideia, mais precisamente, na medida em que ela permite a evolução das formas de pensar, da integração à inclusão. Ele se refere aqui a certos especialistas britânicos, para quem a integração escolar faria apenas referência a medidas técnicas e administrativas, sem acarretar uma mudança radical na escola, em sua cultura e em sua organização, na medida em que se espera que a criança se adapte às estruturas e às práticas existentes. Uma criança oriunda de um estabelecimento especializado que frequenta, em tempo parcial, uma escola regular (mainstream school) permanece, nesta última, um "visitante", e não chega a ser um membro integral da comunidade escolar. Ao revés, a educação inclusiva adota uma postura radical, na medida em que requer que as escolas se transformem em comunidades educativas, nas quais todos os aprendizes são bem-vindos e possuem igualdade de direitos (ARMSTRONG, 1998, p. 53). A inclusão implica assim uma visão diferente da prática educacional, seja na escola ou ainda fora da escola, na medida em que busca adaptar suas práticas à diversidade das crianças, contribuindo a uma acessibilidade geral (KRON e al., 2014, p.20, com um quadro que ilustra as diferenças entre prática integrativa e prática inclusiva).

\section{INCLUSÃO E EDUCAÇÃO INCLUSIVA NO CONTEXTO INTERNACIONAL}

Neste ponto, torna-se muito útil uma análise dos desenvolvimentos internacionais, na medida em que ela permite demonstrar as mudanças profundas entre a educação especial separada e o objetivo da educação inclusiva, que propõe modalidades educacionais no seio das instituições comuns. Fixa-se

\footnotetext{
${ }^{1}$ Definição geral da Educação especial: art 2, I. - modalidade de educação escolar oferecida preferencialmente na rede regular de ensino aos educandos com deficiência, transtornos globais do desenvolvimento e altas habilidades, ou superdotados.

${ }^{2}$ No momento de finalizar este artigo, o Supremo Tribunal Federal formou maioria para criticar e derrubar o decreto presidencial, com o argumento: "a medida incentiva a criação de escolas e classes especializadas para pessoas com deficiência em vez de priorizar a inclusão dos alunos, como determina a Constituição” (18 dez. 2020).
} 
habitualmente o ponto inicial do movimento internacional pela educação inclusiva a partir do encontro de Salamanca, organizado pela UNESCO em 1994, na Espanha, que contou com representantes de 92 países. O quadro de ação então adotado, assim como a declaração final resultante orientaram os governos a ultrapassar os marcos da educação especial e a se engajar em uma educação para todos, em particular junto às crianças com necessidades educativas especiais. O documento se refere explicitamente a "todo adolescente e toda criança, cujas necessidades sejam decorrentes de deficiências ou de dificuldades de aprendizagem". Surgem então as escolas ditas inclusivas, cujo "princípio fundamental [reside em] que todos os alunos de uma comunidade devem, na medida do possível, aprender juntos, sejam quais forem suas deficiências e dificuldades". Tais escolas seriam ainda "o meio mais eficaz de combater as atitudes discriminatórias, ao criar comunidades acolhedoras..."

No entanto, um dos pontos mais importantes dessa declaração é relativamente pouco enfatizado. Nela, não se declara a abolição das instituições especiais. A ideia gira mais em torno de uma modificação do papel dessas instituições, não mais no sentido de atender crianças que sofram diferentes modalidades de segregação, mas sim para ajudar as escolas comuns. Essa parte da declaração merece menção especial, na medida em que ela é capital tanto para criticar o decreto brasileiro de 2020 quanto para definir a nova responsabilidade das instituições especiais em direção às escolas comuns: "Essas escolas especiais podem ser um recurso valioso para o estabelecimento de escolas inclusivas, pois seus profissionais possuem o conhecimento especializado necessário para identificar rapidamente as crianças com deficiência. As escolas especiais também podem servir como centros de formação e recursos para os profissionais regulares da escola. Os investimentos nas escolas especiais existentes devem ser direcionados ao seu novo e mais amplo papel: fornecer apoio profissional às escolas regulares para ajudálas a atender as necessidades educacionais especiais. Nesse sentido, os funcionários das escolas especiais podem dar uma importante contribuição às escolas regulares, ajudando-as a adaptar o conteúdo do currículo e os métodos de ensino às necessidades individuais de seus alunos". (UNESCO, 1994).

Com um salto histórico importante, uma análise dos documentos mais recentes da UNESCO sobre educação nos permitiriam medir as mudanças de perspectiva. Em 2020, a UNESCO publicou dois relatórios sobre as relações entre educação e inclusão. Um deles mostra dados estatísticos precisos coletados em vários países ao redor do mundo. Esta revisão internacional reforça o ponto essencial: a inclusão na educação, assim como as práticas inclusivas, devem ir além das crianças deficientes, além das crianças com necessidades especiais. Elas devem abranger a diversidade dos alunos para construir um sentimento de pertencimento para todos (UNESCO, 2020 a). Nesse sentido, ao invés de ser um problema, a diversidade seria uma oportunidade para realizar mudanças nas práticas educacionais. No entanto, esse relatório constata ainda a existência de uma visão reducionista: entre os países pesquisados, 68\% fornecem uma definição de educação inclusiva, mas $26 \%$ reduzem ainda mais a educação inclusiva às deficiências e às necessidades especiais.

O outro relatório em 2020, denominado Towards Inclusion in Education, busca fazer um balanço das tendências e dos desafios 25 anos depois de Salamanca. Ao examinar o passado, o presente e o futuro do legado de Salamanca, ele busca orientar o desenvolvimento das políticas e das práticas de educação inclusiva. Um fator-chave é mencionado no início do relatório: a afirmação dos direitos humanos como garantia do direito à educação. No entanto, a realidade global está longe de atingir essa meta: cerca de 258 milhões de crianças e adolescentes em todo o mundo não vão à escola. A UNESCO afirma, portanto, a necessidade de promover uma educação inclusiva e equitativa até 2030, bem como dar-lhes condições de aprendizagem ao longo da vida. Dessa forma, a educação inclusiva seria um processo transformador que poderia garantir a plena participação e o acesso de todas as crianças a um aprendizado de qualidade. É preciso, portanto, valorizar a diversidade e eliminar todas as formas de discriminação (fazer aqui menção à nova noção de "interseccionalidade", também em uso no Brasil). No entanto, o relatório considera que o vocabulário da inclusão e o da educação inclusiva nem sempre são bem compreendidos a nível global. Ele reitera que esta definição requer necessariamente um consenso: a inclusão deve ser considerada como um processo que não visa apenas as crianças com deficiência, mas que ajuda fundamentalmente a superar as barreiras que limitam a presença, a participação e o sucesso de todos os aprendizes (learners). Nessas condições, o currículo desenvolvido pelos professores deve promover ambientes de aprendizado que alcancem a diversidade de aprendizes (UNESCO 2020 b). 
Essas diretrizes da UNESCO são muito representativas dos desenvolvimentos nas representações internacionais. Essa descrição poderia ser completada por sucessivos relatórios da OCDE, da Agência Europeia para Necessidades Especiais e Educação Inclusiva, da União Europeia etc. Mas elas podem igualmente ser objeto de análises críticas aprofundadas, em diferentes níveis. Não "a crítica à crítica", no sentido banal do protesto, mas no sentido científico de uma análise apoiada em conceitos operacionais, que inscrevem as noções de inclusão e de educação inclusiva em campos teóricos específicos. Abandonando qualquer pretensão à exaustividade, citemos, por exemplo, os complexos vínculos com as políticas nacionais no contexto econômico neoliberal (SANTANA PAINAUD e KOGHOUT-DIAZ, 2019); a dimensão jurídica com relação ao direito à educação (CURY, 2002); a questão da relação com os outros em suas diversidades, mas também em suas diferenças (LAJONQUIERE, 2020; VOLTOLINI, 2014, 2018; SILVA, 2016: KUPFER, 2017; NABUCO, 2010); a dimensão sociopolítica dos quadros de ação pública (CHAUVIÈRE 2000; PRINZ, 2020).

Responder praticamente a essas mudanças em favor da educação inclusiva não é simples. Com frequência, os professores fazem observações que tocam diretamente as práticas educativas. Eles se perguntam "como agir concretamente para promover a educação inclusiva". Suas críticas são contundentes. Eles afirmam que não basta definir diretrizes generosas, favoráveis ao acolhimento de todos; é preciso, antes de tudo, definir orientações práticas, modos de fazer e procedimentos ${ }^{3}$. Na realidade, essa problemática toca diretamente a formação dos professores, que afirmam com insistência "não estar preparados" para assegurar a complexidade de tal tarefa (PLAISANCE, 2018). Assim, ao abordar a problemática curricular na contemporaneidade, perguntamo-nos se poderíamos definir uma agenda de ação que implique um currículo inclusivo e consequentemente, um tipo de professor que possa responder a tal agenda. Num sentido mais geral, poderíamos formular a questão do seguinte modo: existe realmente um currículo inclusivo? Se existe, que tipo de professor poderia ministrá-lo?

\section{A SOCIOLOGIA DO CURRICULO}

Para desenvolver o que foi dito acima, seria necessário um referencial teórico que, ao permitir a análise do currículo, nos forneça conceitos operacionais que nos permita analisar o real em jogo nas diferentes realidades educativas e em seus imperativos sociais e políticos. Essa estrutura de pensamento é fundamental. Ela é necessária para que estejamos aptos a desenvolver análises do trabalho dos professores, especialmente no que se refere a suas práticas, que apontam no sentido de uma complexidade do currículo. É neste sentido que a sociologia britânica do currículo é uma referência essencial.

Em seu sentido corrente, o currículo é um percurso de formação, um programa ou um plano de estudos. Tal sentido é bastante divulgado nas instituições internacionais e nacionais. Mas essa noção adquiriu um sentido mais rico e mais complexo através da sociologia britânica da educação. Por isso,

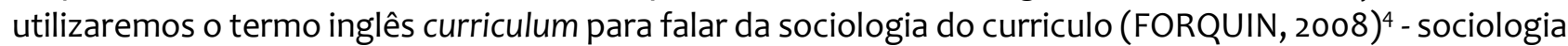
essa que se inscreve no conjunto da nova sociologia da educação britânica do final dos anos 1960. Os sociólogos britânicos dessa época se afastaram das pesquisas baseadas na problemática das desigualdades escolares, em sua relação com as desigualdades sociais. Eles deixam assim de analisar somente as entradas e as saídas do sistema escolar (input e output), a partir apenas de dados quantitativos, como era a tradição da "aritmética política" e passam a analisar o interior da "caixa preta" - the black box - do sistema escolar, ou seja, os processos educativos em ação dentro das instituições, assim como os fenômenos de transmissão cultural dos conhecimentos e seu vínculo com o controle social. A teoria do currículo - the curriculum theory - é uma sociologia crítica, que visa analisar a educação como um empreendimento de transmissão cognitiva e cultural. Seu postulado fundamental é que os conteúdos escolares não são socialmente neutros.

O sociólogo Michael Young marcou o início dessa nova abordagem ao publicar, em 1971, seu livro

\footnotetext{
${ }^{3}$ Poucos trabalhos abordaram diretamente esta questão. Com um vocabulário diferente, Tony Booth e Mel Ainscow buscaram definir modalidades de ação para transformar a educação em um sentido inclusivo, a partir de seu trabalho "Index for Inclusion, Developing Learning and Participation in Schools" (2000).

${ }^{4}$ Curriculum é uma palavra latina, cujo plural é curricula.
} 
Knowledge and control (Conhecimento e controle), cujo desafio era desnaturalizar os saberes escolares, mostrando seu caráter histórico e social, bem como seus efeitos (YOUNG, 1971). Através do exemplo do ensino na Grã-Bretanha, ele construiu uma tipologia de currículos, mostrando o domínio da forte hierarquia do conhecimento, seu caráter livresco e abstrato, que privilegiava o individualismo. Em oposição, ele definiu o conhecimento chamado vocacional (profissional), destinado sobretudo à classe trabalhadora. $O$ "curriculo do futuro" se caracterizaria por sua abertura disciplinar, por sua flexibilidade, por suas conexões entre áreas do conhecimento e pela superação da oposição entre o conhecimento acadêmico e o conhecimento profissional (YOUNG, 1998).

Basil Bernstein, um outro representante importante da sociologia britânica do currículo, mostrou como uma sociedade seleciona, classifica e distribui os conhecimentos destinados ao ensino. Ele distinguiu diferentes códigos de saberes escolares: nos extremos, o que ele denominou um collection code (código fechado), com classificações fortes e conteúdos bem delimitados; e um integrated code (código integrado), cujos conteúdos eram mais abertos, e tanto as classificações quanto o framing (enquadramento) eram bastante mais flexíveis (BERNSTEIN, 1975a) ${ }^{5}$. Essas análises, às vezes consideradas demasiado abstratas, têm, no entanto, consequências fundamentais para a compreensão das práticas de ensino. As classificações e o enquadramento rígido do código fechado estão vinculados a relações docentes autoritárias e hierárquicas, enquanto a flexibilidade do código integrado, tanto nas classificações quanto nos conteúdos do conhecimento, favorece que os professores desempenhem papéis mais flexíveis - sendo, no entanto, igualmente necessário, segundo Bernstein, que as equipes educativas compartilhem uma ideia "integradora", que lhes permita trabalhar em conjunto.

Bernstein estabelece ainda um outra distinção, entre as pedagogias visíveis e invisíveis, e as relações que estas mantém com as diferentes classes sociais (BERNSTEIN, 1975b). Uma pedagogia invisível seria uma pedagogia cujo modo de transmissão é difuso; enquanto uma pedagogia visível se baseia em um modo explícito de transmissão. Bernstein se exprime com muita clareza ao resumir a oposição entre essas duas pedagogias. A pedagogia visível se baseia na seguinte orientação: Things must be kept apart - ou seja, as coisas devem ser mantidas separadas. Já a pedagogia invisível se baseia nesta outra regra latente: Things must be put together (as coisas devem ser pensadas em seu conjunto) (BERNSTEIN, 1977). Neste último caso, cabe ao educador a responsabilidade de organizar o contexto que a criança deve explorar. Por exemplo, nas pedagogias das infant schools (jardins de infância), as formas são mais invisíveis, ou seja, mais flexíveis, pois se apresentam sem rigidez, ao contrário do ensino secundário tradicional. Bernstein toma como exemplo as atividades lúdicas, um conceito essencial da pedagogia invisível nas escolas infantis. Bernstein acrescenta que, do ponto de vista de seu significado social, essa orientação pedagógica coincide com as expectativas culturais e educacionais da nova classe média.

Utilizei a tipologia "visível - invisível" de Bernstein para analisar a evolução da pedagogia das escolas maternais na França desde a Segunda guerra mundial, buscando compreender a evolução da socialização da primeira infância nas escolas e o atendimento generalizado às classes sociais, desde os anos 1960 (PLAISANCE, 1986).

Um dos pontos essenciais da sociologia britânica do currículo é a distinção entre os diferentes tipos de currículo: formal, real, oculto (FORQUIN, 2008; PERRENOUD, 1994: ISAMBERT-JAMATI, 1988). O currículo formal é um currículo prescrito ou intencional, em grande parte presente em textos oficiais, programas de estudos, manuais escolares. Ele consiste na definição do que convém transmitir aos alunos e mesmo do é que preciso avaliar. O currículo oculto designa os aprendizados que não são explicitamente formulados ou desejados, mas fazem parte da experiência do aluno, do seu "ofício" de aluno, como rotinas, maneiras de sair da sala de aula ou de esperar o final da aula etc. Quem usa a excelente expressão "ofício do aluno" é o sociólogo suíço Philippe Perrenoud, para quem ela designa o modo de se comportar e fazer com as regras do jogo escolar, com os "ingredientes" implícitos da socialização na escola (PERRENOUD, 1994). Seus livros estão repletos de muitos exemplos. Finalmente, o currículo real designa

\footnotetext{
${ }^{5}$ A definição do curriculum, segundo Bernstein, é a seguinte: “Qualquer currículo implica um ou mais princípios através dos quais, entre todos os conteúdos possíveis, alguns recebem um estatuto especial e estabelecem uma relação aberta ou fechada entre si (BERNSTEIN, 1967).
} 
o conjunto do aprendizado e das experiências do aluno na escola e em classe, tanto os aspectos diretamente definidos pelo professor quanto aqueles, ocultos, da vida do aluno.

Essas três dimensões são muito úteis para analisar a complexidade das atividades educacionais e para compreender tanto a experiência do aluno quanto o papel do professor. Esta grade analítica parece particularmente relevante para poder responder à questão de um possível currículo inclusivo.

\section{EDUCAÇÃO INCLUSIVA DESDE A PRIMEIRA INFÂNCIA: uma pesquisa de campo na Europa}

É assim dentro dos marcos da análise do currículo que passo a apresentar os resultados essenciais da pesquisa sobre Educação inclusiva desde a primeira infância, realizada em diversos países da Europa. Esse projeto fez parte dos programas europeus de pesquisas conjuntas, nos quais participaram cinco universidades de países distintos: Alemanha (que dirigiu o projeto), Portugal, Suécia, Hungria e França ${ }^{6}$. O objetivo geral do projeto era fornecer material de reflexão sobre as práticas educativas dos profissionais da primeira infância (crianças de menos de 6 anos), que permitisse a melhoria dessas práticas, visando ampliar o mais possível sua participação no processo educativo das crianças ditas "diferentes". Ou seja, esse projeto buscava se abrir à diversidade, seja ela social, subjetiva, ou outra. Isso implica que, segundo as demandas formuladas no quadro do programa europeu Comenius, a pesquisa tinha a perspectiva de atingir variadas propostas de ação visando à melhoria das práticas ou desenvolver sugestões sobre as formações profissionais relacionadas à primeira infância.

A questão geral da pesquisa era a seguinte: quais são os princípios pedagógicos que facilitam a coeducação e a inclusão de crianças com "necessidades especiais" ou com particularidades e singularidades diversas? Mais concretamente, como praticar uma educação em comum, suprimindo as barreiras tradicionais que instituem a separação dos indivíduos? A inclusão era assim definida como um processo que permite a criação de um ambiente educativo apropriado para todos ou ainda como um processo em curso para acolher a real diversidade. A noção de heterogeneidade foi ainda utilizada em um sentido muito próximo, que introduzia explicitamente a dimensão sociocultural das famílias, a diversidade étnica, cultural e socioeconômica, com "seus diferentes sistemas de valores e seus diferentes modelos de relação" (KRON et al., 2014).

De acordo com as orientações internacionais a respeito da educação inclusiva, o elemento essencial não era aquele de adaptar às crianças as instituições educativas existentes e a seus modos de funcionamento, como requer o entendimento tradicional, mas sim aquele de adaptar os conceitos, os programas e as atividades pedagógicas às necessidades e aos interesses de todas as crianças. Esta profunda inversão das práticas requer o desenvolvimento de situações inclusivas, isto é, daquelas situações que permitam estabelecer laços sociais entre todos, enfatizando de modo prioritário o papel decisivo das condições do meio de vida (PLAISANCE, 2017).

Um rápido balanço desse trabalho de pesquisa, no sentido de tentar articular as análises teóricas e os exemplos práticos apresentados, me leva a insistir sobre alguns aspectos.

Em primeiro lugar, trabalhamos para compreender a diversidade dos currículos formais ou prescritos segundos os países. Nossa primeira constatação nos conduz a afirmar que não existe uniformidade entre as organizações dos diferentes países, seus modos de organização, seus modelos pedagógicos e o status de seus profissionais. Sob esse aspecto, não há uniformidade. Por exemplo, na Suécia, o modelo pedagógico se distingue por ser mais familiar, inclusive na organização do espaço. Já na Alemanha, ele é mais centrado no brincar, a partir tanto das diversidades inerentes aos Land (Estados) e sob a inspiração de Frœbel. Na França, existe uma estruturação mais escolar do modelo, inclusive para as crianças pequenas - a partir das orientações curriculares do Ministério da Educação, muito centralizado.

No entanto, foram constatadas convergências fundamentais a respeito do acolhimento da diversidade: diversidade essa que se refere tanto às crianças quanto a suas famílias, particularmente às

\footnotetext{
${ }^{6}$ As referidas universidades eram: Universidade de Siegen (Alemanha), Universidade do Minho/Braga (Portugal), Universidade Mälardalen/Västeras (Suécia), Universidade Eötvös Lorànd/Budapeste (Hungria), Universidade Paris Descartes-Sorbonne/Paris (França).
} 
famílias de imigrantes, no contexto de sociedades europeias cada vez mais heterogêneas. Deu-se igualmente atenção às particularidades individuais, sobretudo as de crianças necessitando ajudas especificas. Em algumas situações observadas, essa exigência requeria o apoio tanto de profissionais suplementares quanto de serviços internos ou externos à instituição (KRON e al. 2014).

O relatório final apresentou muitos elementos concretos do currículo real. As pesquisas de campo realizadas nos diferentes países permitiram a identificação das condições favoráveis às práticas inclusivas (KRON e al, 2014; PLAISANCE, 2017). São elas as seguintes:

1. o trabalho em equipe, que fornece uma sustentação tanto à responsabilidade coletiva, por exemplo, em relação às crianças com grande dificuldade; quanto à flexibilidade das ações dos profissionais em função das necessidades apresentadas;

2. o apoio da direção da instituição e do enquadramento institucional global;

3. o papel do espaço, do número de salas disponíveis, que oferecem possibilidades diversas simultaneamente para as interações entre grupos de crianças e para ações individualizadas;

4. as redes de cooperação com a comunidade local e com os serviços especializados que fornecem ajuda às crianças com necessidades específicas.

\section{UM JARDIM DE INFÂNCIA EM PARIS: que tipo de educação inclusiva?}

Dentro as instituições pesquisadas, figurava a Escola Gulliver, um jardim de infância fundado em 1998 na cidade de Paris - instituição caracterizada por inúmeras originalidades (PLAISANCE, 2017), que passamos a enumerar:

- Seu modo de financiamento público.

- Seu princípio de acolhimento: Em cada três crianças, um lugar era atribuído a crianças com singularidades e particularidades específicas ${ }^{7}$. A instituição permite um acolhimento sem restrições da primeira infância, para ser um lugar aberto a diversidade.

- Seu funcionamento inspirado pela psicoterapia institucional. Essa orientação, ao mesmo tempo teórica e de forte engajamento político, trouxe consequências importantes para a prática clínica e para a educação ${ }^{8}$. No entanto, no caso da Escola Gulliver, convém insistir no fato de que as atividades não tinham natureza psicoterápica, sendo elas apenas pedagógicas. Entretanto, o quadro de trabalho escolhido pela equipe com essa inspiração "institucional”, implicava o desenvolvimento de inúmeras atividades abertas, a ausência de uma hierarquia rígida, a participação de todos no trabalho em equipe e as reuniões de concertação.

Os dois pesquisadores que realizaram as observações e as entrevistas durante a pesquisa feita nessa instituição trabalharam a partir dos princípios da pesquisa etnográfica. Mais precisamente, eles realizaram um trabalho de campo durante um longo período, com interações cotidianas com os profissionais, as crianças e com alguns pais.

Para mostrar um momento de currículo real bem significativo da instituição, passo a apresentar sumariamente uma atividade em que se encontra implicada Rose, uma menininha de sete anos, um pouco mais velha do que as outras, com dificuldades nas relações sociais e diagnosticada como psicótica ${ }^{\text {. A }}$ atividade que observamos era um ateliê de cozinha conduzido por uma educadora, eventualmente secundada por uma outra, em um pequeno espaço, com um grupo reduzido de seis crianças.

\footnotetext{
7 Um terço das crianças era oficialmente reconhecida como portadores de diversos problemas; dois terços delas, consideradas crianças" válidas", não apresentavam problemas particulares.

${ }^{8}$ A psicoterapia institucional tem suas raízes no trabalho realizado no hospital de Saint Alban (sul da França) durante a Segunda Guerra Mundial, em torno da figura central de François Tosquelles. Ela teve seu maior desenvolvimento durante os anos de 1960. Sua perspectiva consistia, essencialmente, em fazer do hospital psiquiátrico um lugar de vida não segregativo e não alienador, com um funcionamento não centralizado. Essa disciplina teve efeitos marcantes na educação, por exemplo, através da pedagogia institucional.

${ }_{9}$ Seu nome real foi facilmente modificado, pois ela usava um casaco cor-de-rosa!
} 


\section{Extrato do diário de campo ${ }^{10}$ :}

A educadora reuniu as crianças ao redor de uma mesa para preparar um bolo... No momento de pegar a farinha para o bolo, Rose coloca a farinha em um recipiente, em seguida sopra com forca sobre esta, que se espalha no ar. A educadora diz que isso é interessante: "Ei! Olhem a Rose! O que ela acabou de fazer? Ela acaba de soprar a farinha, que virou poeira! É tão fina que faz poeira!" Esse momento despertou muito interesse por parte das crianças. Um menino diz: "Posso tentar?" A educadora incita as outras crianças a soprar também sobre a farinha: “Tente, vai! Olhe! Sopre, sopre com forca!”. Finalmente, todas as crianças seguem o exemplo dado por Rose.

Depois Rose deixa o grupo para ir lavar as mãos no lavabo e vai ver a câmera de vídeo que está registrando a sessão. Ela volta para seu lugar com as outras crianças, fica atenta para misturar a farinha com queijo branco, espera sua vez para fazê-lo. Grita um pouco, busca o contato físico, grita de novo, se agita, e depois volta para uma "casinha de brinquedo", de onde ela joga objetos e corre com muito barulho no alto da "casa". Uma outra educadora intervém e cuida de Rose, ficando bem perto dela".

Devemos sobretudo notar que a educadora aceita que Rose não se comporte como os demais, ao manipular a farinha. Ela não "corrige" os comportamentos desviantes, buscando, ao contrário, utilizá-los para adaptá-los a todos, até mesmo incitando os demais a constatar o interesse de soprar a farinha. Ela estimula a partilha da atividade e as interações entre as crianças - o que demonstra uma certa flexibilidade por parte da profissional. Além do papel da educadora principal na oficina de cozinha, uma segunda educadora intervém mais adiante para cuidar de Rose e, mais tarde, toma-a nos braços. A intervenção dessa outra educadora testemunha assim um outro tipo de flexibilidade, no sentido em que vários adultos podem se deslocar de um grupo a outro, caso necessário, se a arrumação do lugar não só o permite - o que é o caso aqui -, como faz mesmo parte do modo de funcionamento do estabelecimento: espaços moduláveis, onde os profissionais não cuidam apenas de um grupo (PLAISANCE, 2017).

Contudo, este exemplo não deve ser tomado como um ideal: os responsáveis deste jardim de infância certamente não aceitariam essa derivação de um modelo a ser reproduzido. Vemos aí pontos de partida e de reflexão para outras experiências em outros contextos e que, por sua vez, podem desenvolver outras condições favoráveis à invenção e à recriação de práticas educativas e institucionais.

\section{UM CURRÍCULO INCLUSIVO?}

Esse exemplo fornece elementos para que possamos aprofundar a questão que tentamos elaborar sobre a validade ou não de um currículo inclusivo.

\subsection{0 currículo inclusivo é flexível.}

Acabamos de ver que uma situação não prevista ocorreu durante as atividades regulares da escola. Essa situação indica um tipo de currículo não programado, diferente, marginal, que a educadora vai utilizar de maneira notável. A atividade não programada torna-se um pretexto para desenvolver uma atividade comum a todo o grupo. A resposta da professora é então contingente ao que possa ocorrer de inesperado. O currículo deve ser suficientemente flexível para permitir as invenções necessárias no cotidiano da instituição. Há uma passagem constante entre o singular e o coletivo e vice-versa (NABUCO, 2010). Não é a criança que deve se adaptar ao currículo. Uma asserção se destaca: a estrutura do currículo inclusivo é flexível, aberto á imprevisibilidade. Está além da rigidez de um programa.

Mas o vocabulário mesmo de "currículo inclusivo" pode parecer restrito em si, sugerindo a ideia de uma programação privilegiada, que conduz a uma uniformização das práticas, o que contrasta com nossa observação anterior. Um currículo inclusivo, no sentido estrito, pode ser um currículo disciplinar, com um programa, uma definição de conteúdos, de atividades etc. Nesse sentido, seria um erro fundamental aplicar aqui um currículo disciplinar universal. A expressão "orientações curriculares inclusivas", mais sensíveis à real diversidade das crianças em questão, seria uma expressão mais adequada, que implicaria uma abertura a reinvenções constantes. Sem dúvida, as flexibilizações curriculares seriam mais adequadas a esse contexto, pois permitiriam que lidássemos com cada caso através de uma constante

\footnotetext{
${ }^{10}$ Ver a descrição detalhada em PLAISANCE, 2017, p. 244.
} 
operacionalidade, dando atenção a cada particularidade que se apresenta. Aqui, o que está em jogo é a singularidade de cada criança. Podemos dizer que o currículo inclusivo é aberto a improvisação, como, por exemplo, a improvisação no jazz no campo musical: há uma temática central, mas também a improvisação, que vem da invenção de cada músico.

Os contextos sociais e culturais nos quais a escola se insere são elementos que compõem a dinâmica da flexibilidade do currículo inclusivo. Para serem verdadeiramente inclusivas, as práticas devem estar voltadas à real pluralidade dos contextos sociais e serem moduladas e diversificadas para responder ao que se apresenta. A flexibilidade se aplica assim, igualmente, à atenção aos contextos situacionais. Por exemplo, não se atua no contexto de uma população composta por grande número de imigrantes como se atua no contexto de uma população nacional tradicional ${ }^{11}$.

Essa definição de uma "orientação curricular inclusiva" difere bastante daquela de "currículo fechado". Ela é, no entanto, da mesma natureza que o código integrado ou a pedagogia invisível de Bernstein, apresentadas anteriormente neste texto: seus conteúdos são mais abertos, suas classificações mais flexíveis e há possibilidade de enquadramento e de autorregulação pelo professor. Muitas pesquisas de campo confirmam esta análise: por exemplo, aquelas efetuadas com crianças que apresentam dificuldades psíquicas. Assim, segundo Eliane Milmann, "as flexibilizações curriculares surgem como uma via de acesso aos processos de inclusão de todos os alunos na rede regular de ensino". Por exemplo, a Lei de diretrizes e bases da educação nacional (LDB), de 1996, enfatiza a dimensão individualizada da criança como sujeito, quando ela diz que "o currículo é o percurso a ser traçado pelo sujeito para entrar no laço social, produzindo um espaço entre o eu e o outro (...) Esse percurso é singular, parte do estudo de cada caso, não havendo receitas ou adequações padronizadas" (MILLMANN, 2017, p.224). A dimensão da criança como sujeito é, portanto, fundamental para preservar a perspectiva inclusiva nas atividades educacionais, ao contrário da aplicação burocrática e uniforme de uma injunção de inclusão ou de uma obrigação pedagógica. Para Rinaldo Voltolini, considerar cada criança como um sujeito é "o lugar decisivo a partir do qual o processo educativo ganha forma" (VOLTOLINI, 2017, p. 181). Ou ainda, segundo Leandro de Lajonquière, que se interroga sobre as dificuldades de incluir uma verdadeira educação nas injunções sobre a inclusão escolar de crianças com dificuldades psíquicas (síndromes psicóticas ou autistas): "Seria preciso ficar atento ao sujeito que se desenvolve na criança, para além do atual rótulo sindrômico que, à sua maneira, recicla o velho espírito de desigualdade" (LAJONQUIÈRE, 2020, p.34).

\subsection{0 currículo inclusivo implica um professor inclusivo}

O exemplo anterior de uma atividade não programada já sugere outra relação do educador com a singularidade de uma criança com dificuldades psíquicas. A flexibilidade da prática observada sugere necessariamente a flexibilidade do próprio educador. Podemos ir mais longe e definir um modelo renovado de professor? ${ }^{12}$ Podemos perguntar: a educação inclusive implica a transformação do papel do professor? Trata-se de um novo professor "inclusivo"? Se sim, quais seriam suas características?

Um primeiro passo foi dado, definindo um professor "reflexivo" e testando a aplicação concreta deste modelo ${ }^{13}$. Um tal professor já se distingue das orientações normativas tradicionais, bem ilustradas pelo vocabulário atribuído às antigas instituições de formação de professores. As chamadas Escolas Normais pretendiam disseminar práticas educacionais o mais homogêneas possíveis, previamente definidas como as melhores, segundo uma padronização das atividades. Contudo, não é certo que este tipo de padronização tenha desaparecido, pelo contrário, porque assumiu outras formas, as da

\footnotetext{
${ }^{11}$ Nesse caso, deve-se analisar o que ocorre na Suíça ou em outros países da Europa, onde a mesma sala de aula permite que o professor possa interagir com crianças que falam 36 línguas diferentes. Cai assim por terra a ideia de que a Europa é constituída por uma base demográfica estável.

${ }^{12} \mathrm{Na}$ parte da história da educação que aborda as crianças em situação de deficiência, valorizou-se sobretudo o papel do professor especializado, cuja ação é tradicionalmente desenvolvida em lugares separados (escolas e classes especiais). A perspectiva da inclusão escolar é radicalmente diferente e indica novos desafios. Não se trata mais de levar apenas em conta a transformação do papel do professor especializado, mas o novo perfil de todo professor, seja ele qual for (PLAISANCE, 2020)

13 "A reflexividade social refere-se à necessidade de estarmos sempre pensando ou refletindo a respeito das circunstâncias em que nossas vidas se desenrolam” (GIDDENS, 2005, p.540).
} 
modernidade, por exemplo o ensino digitalizado, definido a partir de quadros eletrônicos, a imposição de modelos didáticos. que teriam provado seu valor (evidence based practices), ou mesmo as tentativas de definir uma neuro-pedagogia, inspirada em pesquisas cognitivas. (Para uma visão crítica dessa nova normatização, ver CHARLOT, 2020).

Philippe Perrenoud foi quem melhor definiu as orientações para um professor dito reflexivo, a partir do modelo geral sobre a reflexividade e para a educação descrito por Schön (1983, 1992). Um profissional reflexivo possui a capacidade de olhar sobre sua própria prática de maneira crítica: não apenas ele "aceita fazer parte do problema", como "mantém uma relação de envolvimento com sua própria prática... dentro de uma perspectiva de profissionalização" (PERRENOUD, 1999). Um professor, no sentido pleno do termo, é capaz de uma reflexão autônoma e mesmo de ter uma postura de autocrítica e de autoavaliação de suas práticas. Mas além da sala de aula, ele precisa desenvolver outros tipos de participações ativas e críticas: Aprender a cooperar e a atuar em rede. Aprender a viver a escola como uma comunidade educativa. Aprender a sentir-se membro de uma verdadeira profissão e responsável por ela. Aprender a dialogar com a sociedade (PERRENOUD, 1999, 2001; PIMENTA, 2002).

A identificação de um professor " inclusivo » apresentou um novo passo para a modernidade da educação. Esse novo perfil do professor, assim como as novas modalidades de formação estão no centro dos relatórios da UNESCO ou da Agência europeia para a educação inclusiva. Em 2013, a UNESCO definiu a finalidade da educação inclusiva como um processo de mudança e de melhora do sistema educativo em favor da diversidades dos aprendizes. Essa ambição exige que repensemos a formação dos professores para as práticas: trata-se de equipá-los de capacidades práticas, não num sentido puramente teórico, mas de maneira que lhes permita identificar as barreiras à participação e às aprendizagens, para que sejam reflexivos, sejam pensadores críticos capazes de resolver problemas, para que saibam colocar a discriminação em questão. Assim, formar professores para a educação inclusiva significaria que é necessário reconceitualizar seus papéis, suas atitudes e suas competências desde a formação inicial, preparando-os a diversificar seus métodos de ensino, a redefinir suas relações com os colegas e com seus alunos, para capacitá-los a serem co-desenvolvedores do currículo (UNESCO, 2013). O guia da UNESCO sobre o currículo defende a ideia de que é preciso adotar uma visão holística da educação para todos os alunos, ou seja, não se contentar em centrar-se nas necessidades especiais ou nas deficiências, ou ainda não se limitar a propor remediações aos déficits, mas estar atento à totalidade de alunos, particularmente à igualdade entre os gêneros, à educação multilíngue, à aplicação concreta dos direitos humanos nas práticas educativas. O currículo de formação dos professores deve assim ser capaz de combater as discriminações (UNESCO, 2013).

Seguindo a mesma orientação fundamental, a Agência Europeia para as necessidades especiais e a educação inclusiva definiu, em 2012, o perfil do professor inclusivo segundo quatro eixos:

- a valorização da diversidade dos alunos: a diferença entre os alunos é um recurso e uma vantagem para a educação;

- o suporte a todos os alunos: os professores devem ter altas ambições em matéria de sucesso de todos os seus alunos;

- o trabalho coletivo com os outros: a colaboração e o trabalho em equipe são abordagens essenciais para todos os professores;

- dar continuidade à sua formação profissional pessoal de maneira contínua: ensinar é uma atividade que se aprende e os professores devem assumir a responsabilidade de sua própria aprendizagem ao longo da vida (EUROPEAN AGENCY, 2012, p.12).

As análises de vários especialistas em educação se afinam com essas definições de um novo perfil do professor e, de maneira implícita, das novas modalidades de formação. Alguns evocam a necessidade de que os profissionais da educação desenvolvam suas práticas educativas no sentido de uma polimorfia ou de uma polivalência: por exemplo, diante de crianças com atitudes surpreendentes e/ou inesperadas, que os obrigam a trabalhar de forma inovadora, fora dos caminhos usuais. Em alguns casos, esses profissionais devem ter humildade suficiente para reconhecer sua ignorância diante do desconhecido. 
Outros acreditam que o professor deveria ser um "pesquisador", que possa formular várias hipóteses sobre um aluno com dificuldades psíquicas. "Flexibilizar o currículo significa produzir um suporte que facilite a elaboração de hipóteses e o planejamento de situações escolares". Tais flexibilizações não gozam de uma definição uniforme, elas são sempre produzidas "caso a caso", com significantes produzidos pelo aluno em sua singularidade (MILMANN, 2017, p. 226-230).

No que se refere à formação, Rinaldo Voltolini se opõe à utopia racialista que enfatiza a ideologia do rendimento, construída em torno da consolidação de um saber instrumental baseado sobre operações técnicas, e que exclui o papel do sujeito. Em uma bela expressão, ele mostra, ao contrário, que o trabalho docente deve pertencer à ordem da engenhosidade, que inclui uma parte de bricolagem, não sendo mais uma engenharia. (VOLTOLINI, 2017, p.179; apud HAMELINE, 2018, p.56).

Para finalizar, podemos dizer que a nova profissionalização do professor da educação inclusiva com a dinâmica de acessibilidade para todos, implica novos ajustes nas formas de fazer, nas capacidades adaptativas e inovadoras e, fundamentalmente, no questionamento do peso dos padrões escolares uniformes, que colocam em dificuldade os alunos mais vulneráveis e perturbam sua trajetória (PLAISANCE, 2020). Essas abordagens difíceis e inusitadas não desafiam os saberes didáticos, mas os colocam, ao revés, em uma perspectiva crítica, condição sine qua non para que as práticas inovadoras e criativas possam se manifestar.

\section{CONSIDERAÇÕES FINAIS}

A projeto de definir um currículo inclusivo se situa na continuidade da história das instituições e das práticas educativas para crianças com necessidades particulares. Ao invés de uma educação especial separada das escolas comuns e dos programas destinados a todos, as orientações internacionais valorizam cada vez mais a atenção a diversidade das crianças, sob a noção de inclusão ou educação inclusiva. Mas profundas diferenças se manifestam entre os países na aplicação dessas orientações, em função da história de suas próprias instituições, sejam educativas, sanitárias e culturais, e do estado de evolução da formação de professores ligadas a essas abordagens que se dizem não discriminativas para permitir $\mathrm{o}$ acesso as aprendizagens.

É então fundamental não mais se contentar com declarações internacionais gerais, mas de se aproximar de práticas educativas reais. Podemos observar orientações curriculares inclusivas, não em referência a um modelo estandarte e uniforme, mas muito mais na flexibilidade das práticas, na atenção aos imprevistos e a diversidade das situações educativas e das crianças mesmo. Nessas condições, um professor dito inclusivo deve ser necessariamente aberto a invenção de práticas e a uma parte de improvisação necessária, mas isso envolve modalidades de formação radicalmente diferentes de um modelo tradicionalmente normativo. Nessa direção, a educação inclusiva não é dada enquanto tal, mas se apresenta como um processo sempre em curso, a ser defendido e construído.

\section{REFERÊNCIAS}

ARMSTRONG, Felicity. Curricula, 'Management' and Special and Inclusive Edu- cation. In CLOUGH, Peter (Org.). Managing Inclusive Education: from Policy to Experience. London: Paul Chapman, 1998. p. 48-63.

BARTON, Len; ARMSTRONG, Felicity (Orgs). Policy, Experience and Change: cross-cultural reflections on inclusive education. Dordrecht: Springer, 2007.

BERNSTEIN, Basil. Open schools-open society, New Society, 1967, p.351-353.

BERNSTEIN, Basil. On the Classification and Framing of Educational Knowledge. In YOUNG M.F.D., Knowledge and Control, London: Collier Macmilan, 1971, p.47-69.

BERNSTEIN, Basil. On the curriculum, Class, Codes and Control, vol 3, cap 4, London: Routledge and Kegan Paul, 1975a, p.79-84.

BERNSTEIN, Basil. Class and pedagogies: visible et invisible, In Class, Codes and Control, vol 3. cap 6, Towards a Theory of Educational Transmissions, London : Routledge and Kegan Paul, 1975b, p. 116-156.

BOOTH Tony; AINSCOW Mel. Index for Inclusion: Developing Learning and Participation in Schools, 
Bristol: Centre of Studies for Inclusive Education, 2000.

BRASIL, Presidência da Republica. Política nacional de educação especial: equitativa, inclusiva e com aprendizado ao longo da vida. Decreto $n^{\circ} 10.502$, de 30 de setembro de 2020.

CARVALHO, Rosita Édler. Escola inclusiva: a reorganização do trabalho pedagógico. Porto Alegre: Editora Meditação, 2008.

CHAUVIÈRE, Michel. Naissance et conséquences d'un nouveau référentiel pour l'action publique. In BARRAL, Catherine; PATERSON, Florence; STIKER, Henri-Jacques; CHAUVIÈRE, Michel (Orgs.).

L'institution du handicap: le rôle des associations. Rennes: Presses Universitaires de Rennes, 2000, p. 245-249.

CURY, Carlos Roberto Jamil. Direito à educação: direito à igualdade, direito à diferença. Cadernos de Pesquisa. (Fundação Carlos Chagas, São Paulo), n. 116, jul. 2002, pp. 245-262.

CURY, Carlos Roberto Jamil. Réflexions sur les principes juridiques de l'éducation inclusive au Brésil. Égalité, droit à la différence, équité. Recherche et formation pour les professions de l'éducation. n. 61 , 2009, p. 41-53.

CHARLOT, Bernard. Educação ou barbárie? Uma escola para a sociedade contemporânea. São Paulo: Cortez editora, 2020 [Education ou barbarie. Pour une anthropo-pédagogie contemporaine. Paris: Economica/Anthropos, 2020].

EBERSOLD, Serge. Autour du mot « Inclusion». Recherche et formation pour les professions de l'éducation, n. 61, 2009, p. 71-83.

EBERSOLD, Serge; PLAISANCE, Éric; ZANDER, Christophe. Ecole inclusive pour les élèves en situation de handicap: accessibilité, réussite scolaire et parcours individuels. Rapport de Conférence de comparaisons internationales. Paris: Conseil national d'évaluation du système scolaire-CNESCO, 2016.

EBERSOLD, Serge (Org). Accessibility or Reinventing Education. London: ISTE / Wiley Editions, 2020.

EUROPEAN AGENCY FOR DEVELOPMENT IN SPECIAL NEEDS EDUCATION. Teacher Education for Inclusion: profile of inclusive teachers. Odense, Denmark: European Agency for Development in Special Needs Education, 2012.

FIGUEIREDO, Rita Vieira de; BONETI, Lindomar Wessler; POULIN, Jean-Robert (Orgs.). Novas luzes sobre a inclusão escolar. Fortaleza: Edições UFC, 2010.

FORQUIN, Jean-Claude. Les sociologues de l'éducation américains et britanniques: Présentation et choix de textes. Bruxelles : De Boeck et Larcier, 1997.

FORQUIN, Jean-Claude. Sociologie du Curriculum, Rennes : Presses Universitaires de Rennes, 2008.

GARDOU, Charles. La société inclusive, parlons-en! II n'y a pas de vie minuscule. Toulouse: Erès, 2012 [em português: A sociedade inclusiva. Falemos dela! Nao há vida minúscula. Belo Horizonte: Editora UFMG-Fino Traço Editora, 2018].

GIDDENS, Anthony. Sociologia, Porto Alegre: Artmed, 2005 [Sociology, Oxford: Blackwell Publishing, 2001].

ISAMBERT-JAMATI Viviane. Les savoirs scolaires. Enjeux sociaux des contenus d'enseignement et de leurs réformes, Paris : Éditions universitaires, 1988.

KRON, Maria; PLAISANCE Éric (Orgs). Grandir ensemble: l'éducation inclusive dès la petite enfance. Suresnes: Institut National Supérieur de Formation et de Recherche pour L'éducation des Jeunes Handicapés et les Enseignements Adaptés (INSHEA), 2012.

KRON, Maria; SERRANO, Ana Maria; AFONSO, Joana Lima (Orgs). Crescendo juntos. Passos para a inclusão na educação da infância. Porto: Porto Editora, 2014.

KUPFER, Maria Cristina; PATTO, Maria Helena Souza; VOLTOLINI Rinaldo (Orgs). Práticas inclusivas em 
escolas transformadoras: acolhendo o aluno-sujeito, São Paulo: Editora Escuta, 2017.

LAJONQUIÈRE, Leandro de. Figuras do infantil: A Psicanálise na vida cotidiana com as crianças. Petrópolis: Vozes, 2010.

LAJONQUIERE, Leandro de. Pour que l'éducation soit au rendez-vous dans l'inclusion scolaire, Psychologie clinique, n.50, 2020, p.25-35. [Numero special sous la direction de llaria Perone, Enjeux d'inclusion à l'école : regards psychanalytiques].

MANGEZ, Eric; LIENARD, Georges. Sociologie du curriculum In van ZANTEN, Agnès, Dictionnaire de l'éducation, Paris: PUF, 2008, p. 103-107.

MICHAILAKIS, Dimitris; REICH, Wendelin. Dilemmas of Inclusive Education. Alter: Revue européenne de recherche sur le handicap. vol. 3, n. 1, 2010, p. 24-44. DOI: https://doi.org/10.1016/j.alter.2008.10.001.

MILMANN Elaine. Eixos para as flexibilizações curriculares no contexto da educação inclusiva. In KUPFER, Maria Cristina; PATTO, Maria Helena Souza; VOLTOLINI Rinaldo (Orgs), Práticas inclusivas em escolas transformadoras: acolhendo o aluno-sujeito, São Paulo: Editora Escuta, 2017, p.221-230.

NABUCO, Maria-Eugenia. Práticas institucionais e inclusão escolar. Cadernos de Pesquisa, v. 40, n. 139, 2010, p. 63-74.

NEVES RODRIGUES, Libéria; RAHME FARID, Monica; FERREIRA JATOBA MERCES da ROCHA, Carla. Política de Educação Especial e os desafios de uma perspectiva inclusiva. Educação e Realidade. vol. 44, n. 1, 2019 p. 1 - 21.

PELLETIER, Liliane. Le concept d'inclusion et ses défis. Ressources, n. 22, 2020 p.10-29.

PEREZ, Jean-Michel; ASSUDE, Teresa (Orgs.). Pratiques inclusives et savoirs scolaires, Nancy: Éditions universitaires de Lorraine, 2013.

PERRENOUD, Philippe. Métier d'élève et sens du travail scolaire. Paris: ESF, 1994.

PERRENOUD, Philippe. Formar professores em contextos sociais em mudança. Prática reflexiva e participação crítica, Revista Brasileira de Educaçao, n²12, 1999, p.5-21.

PERRENOUD, Philippe. Ensinar: Agir na urgência, decidir na incerteza. Saberes e compêtencias em uma profissão complexa. Porto Alegre: Artmed Editora, 2001.

PIMENTA, Selma Garrido; GHEDIN, Evandro. Professor reflexivo no Brasil. Gênese crítica de um conceito. São Paulo: Cortez Editora, 2002.

PLAISANCE, Éric. L'enfant, la maternelle, la société. Paris: Presses Universitaires de France, 1986.

PLAISANCE, Éric. Da educação especial à educação Inclusiva: esclarecendo as palavras para definir as práticas. Educação, v.38, n.2, 2015, p.231-238.

PLAISANCE, Éric. Os desafios da educação inclusiva e o mal estar na educação, In: VOLTOLINI, Rinaldo (Org). Retratos do mal-estar contemporâneo na educação. São Paulo: Editora Escuta Ltda, 2014, p. 2342.

PLAISANCE, Éric. A educação inclusiva, gênese e expansão de uma orientação educativa: o caso francês. In FERREIRA, Carla Mercês da Rocha Jatobà; DINIZ Margareth; FERRAZ, Claudia Itaborahy (Orgs). As diferenças transitam na escolas. Jundai: Paco Editorial, 2016, p. 111-129.

PLAISANCE, Éric. Quais são as práticas inclusivas de educação no mundo contemporâneo? Análises críticas e perspectivas de ação". In KUPFER, Maria Cristina; PATTO, Maria Helena Souza; VOLTOLINI Rinaldo (Orgs), Práticas inclusivas em escolas transformadoras: acolhendo o aluno-sujeito, São Paulo:Editora Escuta, 2017, p.229-246.

PLAISANCE, Éric. Não estamos preparados para isso !" Educação inclusiva e formação de professores, In VOLTOLINI, Rinaldo (Org).Psicanálise e formação de professores. Antiformação docente, São Paulo: Zagodoni Editora, 2018, p.111-124. 
PLAISANCE, Éric. The Reconfiguration of the Teacher Profession within the Dynamics of Accessibility In: EBERSOLD, Serge (Org). Accessibility or Reinventing Education. Chap 7, London: ISTE / Wiley Editions, 2020.

PRINZ, Antoine. L'inclusion : clarification d'un champ notionnel, Mots. Les langages du politique, n.122 | 2020. DOI : https://doi.org/10.4000/mots.26180.

RAHME, Mônica Maria Farid. Inclusion et internationalisation des droits à l'éducation: les expériences brésilienne, nord-américaine et italienne. La nouvelle revue de l'adaptation et de la scolarisation, n. 64, 2013, p. 223-240.

ROCHEX, Jean Yves. Décrire et analyser la production des inégalités scolaires : l'apport de la sociologie de Basil Bernstein, Perspectiva, Florianópolis, v. 38, n. 3, 2020 p. 01-22. DOI:

http://dx.doi.org/10.5007/2175-795X.2020.e70071.

RODRIGUES, David (Org). Perspectivas sobre a inclusão: de educação à sociedade. Porto: Porto Editora, 2003.

SANTANA PAINAUD Keyla; KOHOUT-DIAZ Magdalena. Análise sobre a implantação da política inclusiva na França e no Brasil: impactos das orientações supranacionais e efeitos sobre a gestão escolar, Revista Educação Online, Rio de Janeiro, n. 32, 2019, p. 44-58.

SCHÖN, Donald. The Reflective Practionner. Nova York: Basic Books, 1983.

SCHÖN, Donald. Formar professores como profissionais reflexivos. In NOVOA Antonio (Org). Os professores e sua formação. Lisboa: Dom Quixote, 1992, p.77-92.

SILVA, Kelly Cristina Brandao da. Educação inclusiva. Para todos ou para cada um? Alguns paradoxos (in)convenientes, São Paulo: Escuta/Fapesp, 2016.

THOMAZET, Serge. L'intégration a des limites, pas l'école inclusive. Revue des Sciences de l'Éducation, vol 34, n.1, 2008, p.123-139.

UNESCO. Déclaration de Salamanque sur les Principes, les Politiques et les Pra- tiques en Matière d'Éducation et de Besoins Educatifs Spéciaux, 1994.

UNESCO. Promoting Inclusive Teacher Education. Advocacy Guides, Paris: Unesco, 2013.

UNESCO. L'éducation inclusive: une formation à inventer. Actes du colloque international. Paris: UNESCO, 17-18 octobre 2013. UNESCO, 2014.

UNESCO. Inclusion and education: all means all. Global Education Monitoring Report. Paris: Unesco, 2020 a.

UNESCO. Towards Inclusion in Education, Paris: Unesco, 2020 b.

VALLE, Ione Ribeiro. Sociologia da educação: Curriculo e saberes escolares. Florianopolis : Editora UFSC, 2011.

VOLTOLINI, Rinado (Org.). Retratos do Mal-Estar Contemporâneo na Educação. São Paulo: Editora Escuta Ltda., 2014.

VOLTOLINI, Rinaldo. Formação de professores e psicanalise. In KUPFER, Maria Cristina; PATTO, Maria Helena Souza; VOLTOLINI Rinaldo (Orgs), Práticas inclusivas em escolas transformadoras: acolhendo o aluno-sujeito, São Paulo: Editora Escuta, 2017, p. 71-188.

VOLTOLINI R. (Org). Psicanálise e formação de professores. Antiformação docente, São Paulo: Zagodoni Editora, 2018.

VOLTOLINI, Rinaldo. Interpelações Éticas à Educação Inclusiva. Educação e Realidade. vol. 44, n. 1, 2019, p. 1-8.

YOUNG Michael. Towards a Sociological Approah of the Curriculum, Thesis, University of Essex, 1967. 
YOUNG Michael. Knowledge and Control: New Directions for the Sociology of Education. London: Collier-Macmilan, 1971.

YOUNG Michael. The Curriculum of the Future. From the "New sociology of Education" to a Critical Theory of Learning. London: Falmer Press, 1998. 